\section{BMJ Open Respiratory Research}

\title{
Trajectory of inhaled cadmium ultrafine particles in smokers
}

\author{
Einat Fireman Klein (D) , ${ }^{1,2}$ Ilan Klein, ${ }^{1,3}$ Omer Ephrat, ${ }^{1,3}$ Yoram Dekel, ${ }^{1,3}$ \\ Aharon Kessel, ${ }^{1,4}$ Yochai Adir ${ }^{1,2}$
}

To cite: Fireman Klein E, Klein I, Ephrat 0, et al. Trajectory of inhaled cadmium ultrafine particles in smokers. BMJ Open Resp Res 2021;8:e001000. doi:10.1136/ bmjresp-2021-001000

EFK and IK contributed equally.

Received 17 June 2021 Accepted 9 November 2021

Check for updates

C) Author(s) (or their employer(s)) 2021. Re-use permitted under CC BY-NC. No commercial re-use. See rights and permissions. Published by BMJ.

${ }^{1}$ B. Rappaport Faculty of Medicine, Technion- Israel Institute of Technology, Haifa, Israel

${ }^{2}$ Pulmonary Division, Lady Davis Carmel Medical Center, Haifa, Israel

${ }^{3}$ Department of Urology, Lady Davis Carmel Medical Center, Haifa, Israel

${ }^{4}$ Division of Clinical Immunology and Allergy, Bnai Zion Medical center, Haifa, Israel

Correspondence to Dr Einat Fireman Klein; einatfire@gmail.com

\section{ABSTRACT}

Introduction Tobacco smoking is a significant source of cadmium exposure among smokers. Most of inhaled heavy metals, including cadmium, are attached to ultrafine particles (UFPs) surface. A low inhaled UFP content in exhaled breath condensate reflects a high inflammatory status of airways. Increased respiratory epithelial permeability and translocation to the circulation is the proposed mechanism. UFP recovered from smokers' airways have high levels of cadmium compared with the airways of non-smokers.

Methods Urine was collected from 22 smokers subjects and 43 non-smokers. Samples were analysed for UFP and cadmium content. UFP were measured in urine samples by means of the NanoSight LM20 system (NanoSight, UK). A Niton XL3 X-ray fluorescence spectrometer analyzer (Thermo Fischer Scientific, Germany) quantified heavy metal contents in the urine samples.

Results Smokers had elevated UFP and cadmium content in urine compared with non-smokers $(4.6 \mathrm{E} 8 / \mathrm{mL}$ and $20.6 \mathrm{ppm}$ vs $3.4 \mathrm{E} 8 / \mathrm{mL}$ and $18.5 \mathrm{ppm}, \mathrm{p}=0.05$ and $p=0.05$, respectively). Smokers had elevated levels of lead and rubidium compared with non-smokers (8.9 ppm and $27 \mathrm{ppm}$ vs $7.8 \mathrm{ppm}$ and $2 \mathrm{ppm}, \mathrm{p}=0.05$ and $p=0.04$, respectively)

Discussion We suggest that the trajectory of cadmiumrelated UFP in smokers begins by its inhalation into the airways. The UFPs induce inflammation and oxidative stress in the small airways, are subsequently translocated from the interstitium to the circulation and are finally detected and secreted in urine

\section{INTRODUCTION}

Long-term exposure to cadmium has systemic effects, including pulmonary and renal toxicity. Exposure to cadmium primarily occurs through the ingestion of contaminated food and water, however, inhalation is considered the main route of exposure among smokers due to the accumulation of cadmium in the tobacco plant (Nicotiana tabacum). ${ }^{1}$ Apart of cadmium, cigarette smoking causes exposure to several heavy metals including arsenic, chromium, nickel and lead. ${ }^{2}$ The majority of inhaled heavy metals, are attached to the surface of ultrafine particles (UFP), allowing the induction of oxidative stress and eventually carcinogenic
Key messages

In this study, we investigated the extent to which smoking-related cadmium particles travel when inhaled.

- The suggested trajectory of cigarette-related inhaled cadmium-UFP started from the lungs and ended in the urinary system.

- Understanding how inhaled cadmium travels will provide more information on its toxicity.

effects in lung tissue. ${ }^{3}$ Inhaled UFPs are smallsized particles with toxic effects due to their large surface area and high penetration rate into deep lung compartments and the circulation. We had recently shown that UFP recovered from smokers' airways have high levels of cadmium compared with the airways of non-smokers. ${ }^{4}$ We demonstrated that biological monitoring of UFP concentrations in exhaled breath condensate (EBC) could be a reliable indicator of high PM2.5 exposure levels. Moreover, we had also observed that low UFP contents in EBC reflected a high airway inflammatory state and that the UFP level may serve as a novel marker of exacerbation risk in patients with chronic obstructive pulmonary disease (COPD). ${ }^{45}$ The suggested mechanism behind those observations is that a healthy intact epithelial barrier should reduce the translocation of particles, while increased epithelial permeability in inflamed airways, will allow more UFP to penetrate and translocate into the circulation. The findings of low UFP concentrations in EBC and high UFP concentrations in the serum of COPD patients compared with healthy controls serve to support our hypothesis. ${ }^{5}$ The concept that UFP translocate to circulation was first proposed by the findings of a murine model in which the induction of lung inflammation resulted in a shift of the UFP pattern towards larger particles, a process which can be explained by translocation of smaller particles thorough inflamed epithelium. ${ }^{6}$ In order to further investigate the trajectory of 


\begin{tabular}{|c|c|c|c|c|}
\hline Characteristic (n) & $\begin{array}{l}\text { Ultrafine particles } \\
\text { Concentrations }\left(\mathrm{E}^{8} / \mathrm{mL}\right)\end{array}$ & $P$ value & Cadmium level (ppm) & $P$ value \\
\hline \multicolumn{5}{|l|}{ Age, years } \\
\hline$<66(29)$ & $3.4 \pm 2.1$ & 0.15 & $19.1 \pm 3.6$ & 0.15 \\
\hline$\geq 66(36)$ & $4.2 \pm 2.6$ & & $19.3 \pm 4.6$ & \\
\hline \multicolumn{5}{|l|}{ Sex } \\
\hline M (52) & $3.9 \pm 2.5$ & 0.5 & $19.3 \pm 3.5$ & 0.76 \\
\hline$F(13)$ & $3.4 \pm 1.84$ & & $18.9 \pm 6.3$ & \\
\hline \multicolumn{5}{|c|}{ Prior transurethral carcinoma } \\
\hline Yes (32) & $3.6 \pm 2.35$ & 0.5 & $19.5 \pm 4.8$ & 0.55 \\
\hline No (33) & $4 \pm 2.5$ & & $18.9 \pm 3.5$ & \\
\hline \multicolumn{5}{|l|}{ Smoking status } \\
\hline Past/active (22) & $4.6 \pm 2.1$ & 0.05 & $20.6 \pm 4.1$ & 0.05 \\
\hline Non-smoker (43) & $3.4 \pm 2.5$ & & $18.5 \pm 4$ & \\
\hline \multicolumn{5}{|c|}{ Occupational exposure* $\ddagger$} \\
\hline Yes (7) & $5.4 \pm 3.2$ & 0.07 & $21.8 \pm 3.1$ & 0.08 \\
\hline No (58) & $3.65 \pm 2.3$ & & $18.9 \pm 4.2$ & \\
\hline \multicolumn{5}{|c|}{ Chronic lung disease $†$} \\
\hline Yes (5) & $2.4 \pm 2.4$ & 0.16 & $19.6 \pm 2.5$ & 0.8 \\
\hline No (60) & $3.9 \pm 1.5$ & & $19.2 \pm 4.3$ & \\
\hline \multicolumn{5}{|l|}{ Culture } \\
\hline Positive (10) & $2.8 \pm 1.7$ & 0.13 & $18.3 \pm 3.5$ & 0.46 \\
\hline Negative (55) & $4 \pm 2.5$ & & $19.4 \pm 4.3$ & \\
\hline \multicolumn{5}{|l|}{ Antibiotics } \\
\hline Yes (5) & $3.1 \pm 2.1$ & 0.47 & $17.6 \pm 3.3$ & 0.38 \\
\hline No (60) & $3.9 \pm 2.4$ & & $19.3 \pm 4.2$ & \\
\hline \multicolumn{5}{|l|}{ Irrigations } \\
\hline Yes (24) & $3.5 \pm 2.4$ & 0.4 & $19.6 \pm 5.5$ & 0.6 \\
\hline No (41) & $4 \pm 2.43$ & & $19 \pm 3.2$ & \\
\hline \multicolumn{5}{|l|}{ Cystoscopy findings } \\
\hline Yes (16) & $3.8 \pm 1.8$ & 0.98 & $18 \pm 6.1$ & 0.19 \\
\hline No (49) & $3.8 \pm 2.6$ & & $19.6 \pm 3.3$ & \\
\hline \multicolumn{5}{|l|}{ Pathology } \\
\hline Malignant (15) & $4.2 \pm 2.4$ & 0.8 & $17.9 \pm 5.9$ & 0.4 \\
\hline Normal (5) & $4.5 \pm 2.2$ & & $20.3 \pm 4.2$ & \\
\hline
\end{tabular}

${ }^{*}$ Occupational exposure to dye, asbestos, dust, fuel, sawdust, nitrogen acid, acetone, sand, glue, smoke, heavy metals welding, plastic and/or coal. †Emphysema and/or bronchiectasis.

$\ddagger$ A minimum of 1 year of exposure was taken as positive.

F, female; M, male.

cadmium-related UFP, we analysed UFP and heavy metal contents in urine samples of smokers compared with non-smokers.

\section{METHODS}

Our study included 65 subjects of whom 22 were active or past smokers and 43 were non-smokers who served as the control group. The study subjects had been referred to undergo diagnostic cystoscopy due to benign and oncological reasons.The participants filled in clinical and occupational questionnaires, and urine samples were collected prior to the cystoscopy. All subjects avoid smoking for at least 1 hour before urine was collected. The samples were centrifuged for $5 \mathrm{~min}$ at $4000 \mathrm{RPM}$, and fluid was separated and stored at $-20^{\circ} \mathrm{C}$ until analysis. UFPs were measured in urine samples by means of the NanoSight LM20 system (NanoSight, UK). A Niton XL3 X-ray fluorescence (XRF) spectrometer analyser (Thermo Fischer Scientific, Germany) quantified heavy metal contents in the urine samples. XRF analyzers determined the presence and quantity of heavy metals in urine by measuring the specific fluorescent X-ray emitted from 


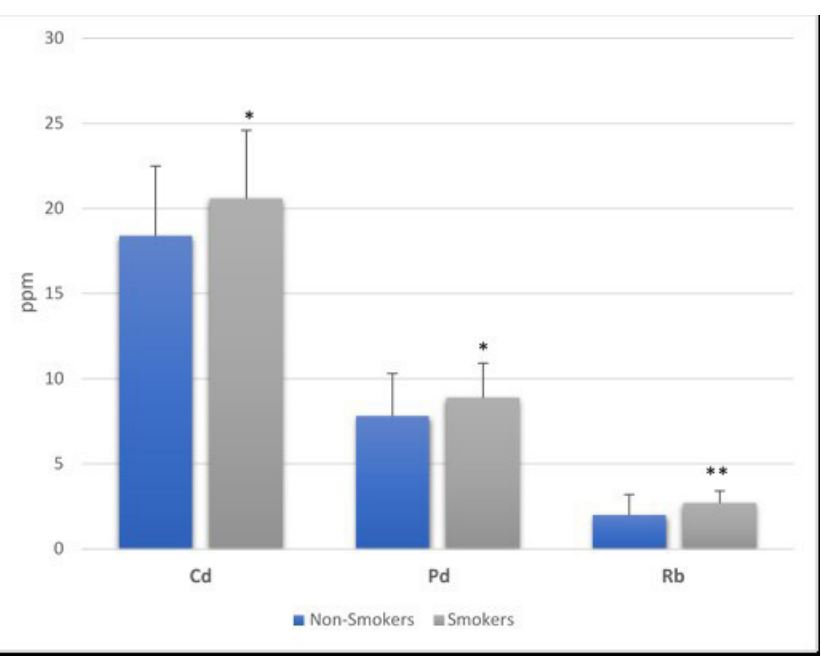

Figure 1 Heavy metal levels in urine samples of smokers and non-smokers. ${ }^{*} \mathrm{P}=0.05,{ }^{\star *} \mathrm{p}=0.01$. $\mathrm{CD}$, cadmium; PD, lead; PPM, particles per million; Rb, rubidium.

the sample when excited by a primary X-ray source. Each sample was scanned twice in different areas, and the average of two repeated measurements was calculated. Detectable chemicals should have a concentration at least three times the SD of the measurement.

\section{PATIENT AND PUBLIC INVOLVEMENT}

Patients are not directly involved in the design and conception of this study.

\section{RESULTS}

The smokers had elevated UFP concentrations and cadmium levels in urine compared with the non-smokers $(4.6 \pm 2.1 \mathrm{E} 8 / \mathrm{mL}$ and $20.6 \pm 4.1 \mathrm{ppm}$ vs $3.4 \pm 2.5 \mathrm{E} 8 /$ $\mathrm{mL}$ and $18.5 \pm 4 \mathrm{ppm}, \mathrm{p}=0.05$ and $\mathrm{p}=0.05$, respectively).

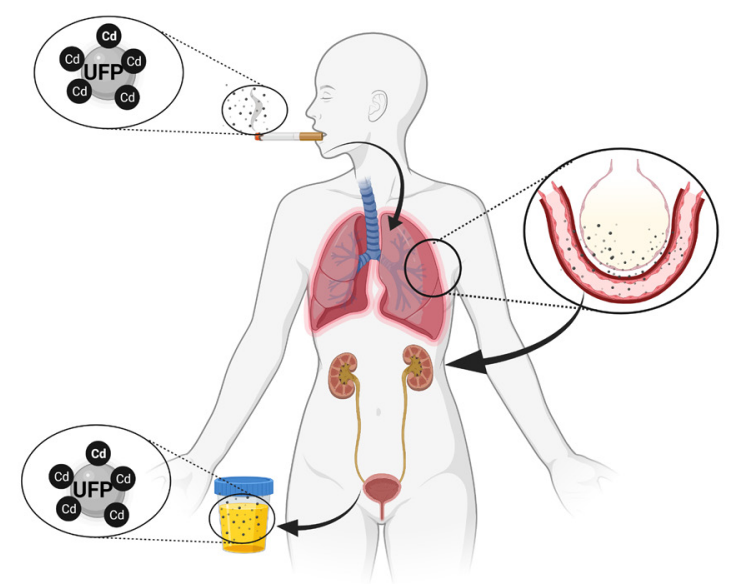

Figure 2 Trajectory of inhaled ultrafine particles (UFP). The trajectory of cadmium-related UFP in smokers begins by its inhalation into the airways. The UFP induce airways inflammation, are subsequently translocated from the interstitium to the circulation and are finally secreted and detected in urine. Created with BioRender.com.
No difference in glomerular filtration rate (GFR) was calculated in smokers compare to non-smokers (81.4 vs $83.5 \mathrm{~mL} / \mathrm{min} / 1.73 \mathrm{~m}^{2}, \mathrm{p}=0.6$ ). Furthermore, GFR did not correlate with cadmium and UFP in urine. With the exception of smoking status, no clinical characteristics had any significant influence on UFP and cadmium content in urine (table 1). In addition to the findings on cadmium, smokers had elevated levels of lead and rubidium compared with non-smokers $(8.9 \pm 1.6 \mathrm{ppm}$ and $2.7 \pm 0.7 \mathrm{ppm}$ vs $7.8 \pm 2 \mathrm{ppm}$ and $2 \pm 1.2 \mathrm{ppm}, \mathrm{p}=0.05$ and $\mathrm{p}=0.01$, respectively) (figure 1 ). Others elements that were detected in the urine samples included silver, niobium, strontium, tungsten, copper and silicon, and their level did not differ in relation to clinical characteristics.

\section{DISCUSSION}

Our results showed that the trajectory of cigarette-related inhaled cadmium UFP started from the lungs and ended in the urinary system (figure 2). It is known that cadmium in urine reflects long-term exposure, since cadmium in the kidney has a half-life of 10-30 years and is continuously excreted in urine. ${ }^{7}$ Gairola and Wagner demonstrated that the inhalation of cigarette smoke caused an elevation of cadmium in lung and kidney tissue, but not in liver tissue. ${ }^{8}$ Others have reported that smokers have higher levels of cadmium and lead in EBC and urine samples. ${ }^{9}{ }^{10}$ Increased cadmium concentrations were also found in bronchoalveolar lavage and blood samples of smokers compared with nonsmoker controls. ${ }^{1}$ We have also recently shown that healthy smokers had higher cadmium levels in EBC compare to healthy nonsmokers. Additionally, subjects with low UFP concentrations in EBC also had low cadmium levels in $\mathrm{EBC}$ versus subjects with high UFP levels. ${ }^{6}$ This study has several limitations that bear mention, first, since this was a cross-sectional study, reproducibility of the UFP content in urine in the same subject was not evaluated. Second, analysis was limited to urine samples, measurement of cadmium related UFP in EBC and serum in the same subject would provide a more reliable pathway from lungs to urine.

\section{CONCLUSIONS}

We suggest that the trajectory of cadmium-related UFP in smokers begins by its inhalation into the airways (figure 2). The UFPs induce inflammation and oxidative stress in the small airways, are subsequently translocated from the interstitium to the circulation and are finally detected and secreted in urine. Further studies tracking cadmium-related UFP from lungs to urine in the same subjects are needed to confirm our hypothesis.

Contributors Conceptualisation and methodology, writing-review and editing: EFK IK and YA. Formal analysis and data curation: EFK and IK. Investigation: EFK, IK and OE. Resources: IK, OE and YD. Project administration: EFK, IK and YD. Supervision: AK and YA. EFK acts as the guarantor for this study.

Funding The authors have not declared a specific grant for this research from any funding agency in the public, commercial or not-for-profit sectors. 


\section{Competing interests None declared.}

Patient and public involvement Patients and/or the public were not involved in the design, or conduct, or reporting, or dissemination plans of this research.

Patient consent for publication Not applicable.

Ethics approval All subjects signed informed consent forms, and the study was approved by the institutional review board of Carmel Medical Center.

Provenance and peer review Not commissioned; externally peer reviewed.

Data availability statement No data are available.

Open access This is an open access article distributed in accordance with the Creative Commons Attribution Non Commercial (CC BY-NC 4.0) license, which permits others to distribute, remix, adapt, build upon this work non-commercially, and license their derivative works on different terms, provided the original work is properly cited, appropriate credit is given, any changes made indicated, and the use is non-commercial. See: http://creativecommons.org/licenses/by-nc/4.0/.

ORCID iD

Einat Fireman Klein http://orcid.org/0000-0001-8669-1874

\section{REFERENCES}

1 Ganguly K, Levänen B, Palmberg L, et al. Cadmium in tobacco smokers: a neglected link to lung disease? Eur Respir Rev 2018;27:170122-8.
2 Caruso RV, O'Connor RJ Stephens WE, et al. Toxic metal concentrations in cigarettes obtained from U.S. smokers in 2009 results from the International tobacco control (ITC) United States survey cohort. Int J Environ Res Public Health 2013;11:202-17.

3 Li N, Georas S, Alexis N, et al. A work group report on ultrafine particles (American Academy of Allergy, Asthma \& Immunology): Why ambient ultrafine and engineered nanoparticles should receive special attention for possible adverse health outcomes in human subjects. J Allergy Clin Immunol 2016;138:386-96.

4 Fireman Klein E, Adir Y, Krencel A, et al. Ultrafine particles in airways: a novel marker of COPD exacerbation risk and inflammatory status. Int J Chron Obstruct Pulmon Dis 2019;14:557-64.

5 Klein EF, Adir Y, Fireman E, et al. Cigarette-related cadmium and environmental pollution exposure are reflected in airway ultrafine particle content. ERJ Open Res 2020;6:00361-2019.

6 Bar-Shai A, Alcalay Y, Sagiv A, et al. Fingerprint of lung fluid ultrafine particles, a novel marker of acute lung inflammation. Respiration 2015;90:74-84

7 Vacchi-Suzzi C, Kruse D, Harrington J, et al. Is urinary cadmium a biomarker of long-term exposure in humans? A review. Curr Environ Health Rep 2016;3:450-8.

8 Gairola CG, Wagner GJ. Cadmium accumulation in the lung, liver and kidney of mice and rats chronically exposed to cigarette smoke. J Appl Toxicol 1991;11:355-8.

9 Ghio AJ, Madden MC, Esther CR. Transition and post-transition metals in exhaled breath condensate. J Breath Res 2018;12:027112.

10 Richter PA, Bishop EE, Wang J, et al. Tobacco smoke exposure and levels of urinary metals in the U.S. youth and adult population: the National health and nutrition examination survey (NHANES) 19992004. Int J Environ Res Public Health 2009;6:1930-46. 